\title{
Modeling and simulation of quasi-Z-source indirect matrix converter for permanent magnet synchronous motor drive
}

\author{
Ahmed M. Nori, Turki K. Hassan \\ Department of Electrical Engineering, College of Engineering, University of Mustansiriyah, Iraq
}

\begin{tabular}{l} 
Article Info \\
\hline Article history: \\
Received Dec 12, 2018 \\
Revised Jan 26, 2019 \\
Accepted Mar 1, 2019 \\
\hline
\end{tabular}

\section{Keywords:}

Indirect matrix converter (IMC) Permeant magnet synchronous motor (PMSM)

Quasi-z-source indirect matrix converter (QZSIMC)

Shoot through duty ratio (D)

Space vector modulation (SVM)

\begin{abstract}
This paper aims to use a three-phase quasi-Z-source indirect matrix converter (QZSIMC) to expand the voltage gain for application in a Permanent Magnet Synchronous Motor (PMSM) drives. In this converter, a unique quasi-Zsource network (QZSN) connects the three-phase input voltage to conventional indirect matrix converter (IMC) in order to boost the supply voltage for PMSM because of limited voltage gain of IMC. Dual space vector modulation (SVM) is utilized to control the QZSIMC. The amplitude of output voltage for quasi-Z-source network is raised by the shoot-through of the rectifier stage, so the system voltage gain becomes greater. Through selecting the optimized value of shoot through duty ratio (D) and modulation index of the rectifier stage $\left(\mathrm{m}_{-} \mathrm{i}\right)$, the drive system can automatically regulate the output voltage of QZSIMC during conditions of voltage sag, step change in load torque and reference speed change when the required voltage gain of QZSIMC is more than 0.866 depending on input voltage and required output voltage. The vector control technique based on closed loop speed control is proposed to control speed of the motor from zero to rated speed which is combined with the proposed converter to obtain the motor drive. The simulation results with MATLAB /Simulink 2015 are obtained to validate performance of PMSM drive.
\end{abstract}

Copyright (C) 2019 Institute of Advanced Engineering and Science. All rights reserved.

\section{Corresponding Author:}

Ahmed M. Nori,

Department of Electrical Engineering, College of Engineering,

University of Mustansiriyah, Iraq.

Email: ahmedmuthenaa@gmail.com

\section{INTRODUCTION}

The matrix converter (MC) has acquired significant attention in academic and industrial field since the manufacture. The matrix converters introduce power flow in two directions, the waveforms of input and output current are sinusoidal, and the topology of $\mathrm{MC}$ has not a dc-link capacitor, which increases the system lifetime compared with the traditional back-to-back converter $[1,2]$. The MC configurations is divided into direct matrix converter (DMC) and indirect matrix converter, the IMC solves the commutation problems found with utilizing of the DMC [3-5], the implementation of traditional IMC is limited due to: traditional IMC has a constrained voltage ratio less than 0.866 [6]; and the power supply immediately is connected to the load, which may cause disturbance between both sides in each other.

To raise the voltage gain of the traditional IMC, several over-modulation methods have been suggested, they could extend the voltage gain of traditional IMC but at the expense of low frequency harmonics in both input current and the output voltage [7]. latterly, the Z-source IMC (ZSIMC) is proposed through integrating the Z-source network (ZSN) between rectifier and inverter stages of the IMC (in the intermediate DC-link), which is utilized to raise the dc-link voltage of the inverter. However, it needs large capacitors and inductors in the dc-link bus[8],[9]. A family of Z source direct matrix converter (ZSDMC) were suggested, which employed lower number of switches and passive components to boost the voltage gain. But they still need to solve complex commutation of DMC. In this paper, a quasi-Z-source indirect 
matrix converter (QZSIMC) is proposed, which forms by integrating the QZSN to the traditional IMC in the input side of three-phase supply. The QZSN raises the voltage gain, and also it has a smaller size of passive components than the DC-side QZSN. Without complex commutation of the DMC, the control method of the QZS-IMC is simpler. Also, lower switching loss can be achieved through zero current commutation in the rectifier stage [10], [11].

Permanent Magnet Synchronous Motor has many features such as its torque /inertia ratio is high, wide speed range and high efficiency, which make it the most widely AC machine used in application of servo control. PMSM shows the excellent performance in transient and steady state, getting overall research attention and used in the application of different fields such as in robotics, household, aerospace and others [12]. There are many different control strategies for the PMSM motor, most common and effective strategy is vector control or so-called Field oriented control (FOC), which enables PMSM to have a fast response with soft start. The vector control theory is used in PMSM drives with $d-q$ reference frame, hence the controlling of flux and torque is achieved independently, so by applying vector control, the PMSM is equivalent to separately excited DC motor operating in steady state [13]. To improve performance of vector control, various controllers are proposed such as traditional Proportional Integral (PI) controller, Proportional Integral Derivative (PID) controller, fuzzy PI controllers and others [14]. PI controller has been widely employed in the industry because of low cost and small steady-state error [15]. The voltages applied to motor are produced by using two PI controllers with the $d-q$ current signals, which are called as magnetizing loop and as well as torque loop. And mostly, they have no effect with each other. But at high speed, $d$ - and $q$ - axis currents will make marked coupling effect, which will demean overall performance of motor. To eliminate this problem, a motor current decoupling control is used [16]. Space vector modulation is used as a modulation technique for Matrix converter [17]. In this technique, the three phase voltage quantities $\left(v_{a}, v_{b}\right.$, $v_{c}$ ) are transformed to their equivalent two-phase quantities (alpha, beta) by means of Clark's Transformation. Magnitude and angle of the voltage reference vector can be determined from the two-phase quantities to identify sectors [18]. In each sector, the voltage reference vector is located between two active vectors, which are employed to calculate the duty cycles of the switches. Thus, the desired switching signals are generated to control the switches of IMC [19], the whole drive system can be clarified in Figure 1.

In this paper, the QZSIMC-based PMSM drive is illustrated through implementation of simulations under grid voltage sag, variable load and reference speed conditions after the operation principle and analysis of the configuration for the QZSIMC are demonstrated. The vector control is applied to the motor drive system. Simulation results verify ability of proposed converter to vary voltage gain according to required motor speed and load condition.

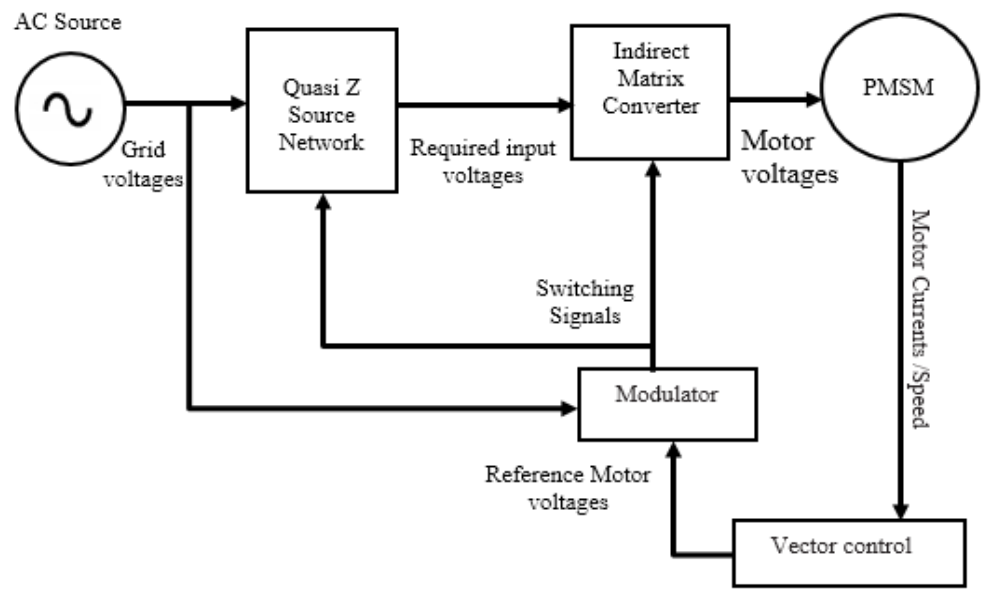

Figure 1. The basic of scheme QZSIMC based drive system

This paper is categorized as follows: The topology and modulation of proposed QZSIMC is presented in Section 2. The circuit analysis of proposed QZSIMC is illustrated in Section 3. The parameters of QZSN are designed in Section 4. The control strategy of shoot through duty radio is showed in Section 5. The mathematical model of PMSM is demonstrated in Section 6. Section 7 explains the vector control of PMSM. QZSIMC based drive system is discussed in Section 8. Section 9 comprises the simulation results of motor drive. And finally, conclusion is made in Section 10. 


\section{TOPOLOGY AND MODULATION OF PROPOSED QZSIMC}

In this paper, the QZSN is used as a booster for dc-link voltage, which connects the three-phase supply voltage with IMC.The input current of this converter is in continuous conduction mode (CCM) because of filtering function of QZSN. The IMC topology of proposed QZSIMC is consisted of two stages; rectifier and inverter stages,and the SVM control strategy is applied for both stages to generate switching signals of the power switches in order to obtain desired source current and output voltage waveforms [20].

\subsection{Proposed topology}

The topology of QZSIMC is shown in the Figure 2, which comprises of five parts: three-phase AC source, QZSN, rectifier stage, inverter stage and AC load. The QZSN is consisted of the six inductors $\left(L_{a 1}\right.$, $\left.L_{a 2}, L_{b 1}, L_{b 2}, L_{c 1}, L_{c 2}\right)$, six capacitors $\left(C_{a 1}, C_{a 2}, C_{b 1}, C_{b 2}, C_{c 1}, C_{c 2}\right)$, and three bidirectional switches $\left(S_{a}, S_{b}\right.$, $\left.S_{c}\right)$. These switches are controlled by applying one gate signal $\left(S_{x}\right)$, since they own the same switching attitude, this unique impedance network enables the proposed QZSIMC to operate in two modes the buck and boost modes [21].

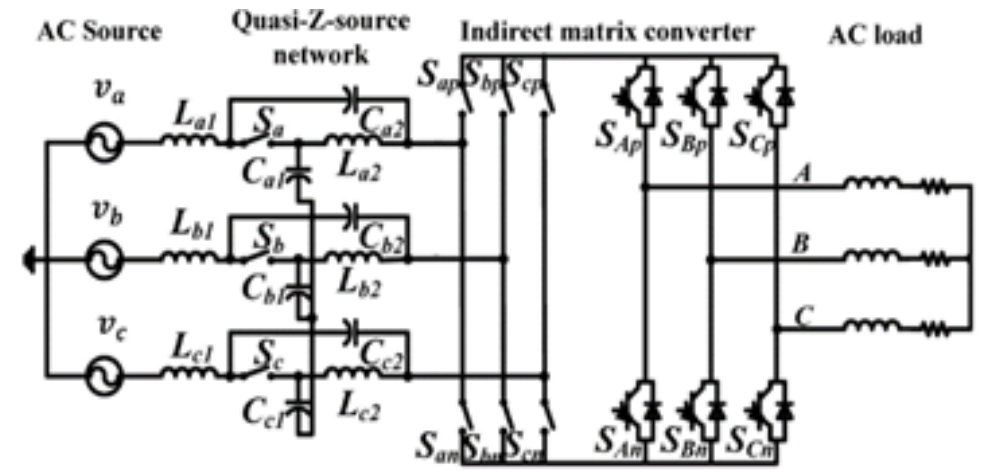

Figure 2. Topology of proposed QZSIMC

\subsection{Space vector modulation}

The grid current-fed SVM can modulate the rectifier stage to obtain sinusoidal input current and controllable input power factor. While, the output voltage-fed SVM is applied in the inverter stage to modulate three-phase output voltage. The modes of the rectifier's switches can be divided into two vector states, active vector and zero vector states. To boost the output voltage of QZSN, the simple boost control method

proposed $[22,23]$, in which the shoot-through zero vector is inserted during zero vector of rectifier stage, as shown in Table I. In this state, the three-phase supply voltage is short-circuited to obtain voltage boost [24]. By taking sector 1 as an example, the vector reference of input current $I_{r e f}$ is formed by vectors $I_{a b}$ and $I_{a c}$, as shown in the Figure 3.

Table 1. Input current vectors, switching combinations and DC-link voltage

\begin{tabular}{lcccccccll}
\hline $\mathrm{N}$ & $\mathrm{V}_{\mathrm{dc}}$ & $\mathrm{S}_{\mathrm{a}_{\mathrm{p}}}$ & $\mathrm{S}_{\mathrm{b}_{\mathrm{p}}}$ & $\mathrm{S}_{\mathrm{c}_{\mathrm{p}}}$ & $\mathrm{S}_{\mathrm{a}_{\mathrm{n}}}$ & $\mathrm{S}_{\mathrm{bn}}$ & $\mathrm{S}_{\mathrm{cn}}$ & Vector & Vector meaning \\
\hline 1 & $\mathrm{~V}_{\mathrm{ac}}$ & 1 & 0 & 0 & 0 & 0 & 1 & $\mathrm{I}_{\mathrm{ac}}$ & Active vector \\
2 & $\mathrm{~V}_{\mathrm{bc}}$ & 0 & 1 & 0 & 0 & 0 & 1 & $\mathrm{I}_{\mathrm{bc}}$ & Active vector \\
3 & $-\mathrm{V}_{\mathrm{ab}}$ & 0 & 1 & 0 & 1 & 0 & 0 & $-\mathrm{I}_{\mathrm{ab}}$ & Active vector \\
4 & $-\mathrm{V}_{\mathrm{ac}}$ & 0 & 0 & 1 & 1 & 0 & 0 & $-\mathrm{I}_{\mathrm{ac}}$ & Active vector \\
5 & $-\mathrm{V}_{\mathrm{bc}}$ & 0 & 0 & 1 & 0 & 1 & 0 & $-\mathrm{I}_{\mathrm{bc}}$ & Active vector \\
6 & $\mathrm{~V}_{\mathrm{ab}}$ & 1 & 0 & 0 & 0 & 1 & 0 & $\mathrm{I}_{\mathrm{ab}}$ & Active vector \\
7 & 0 & 1 & 0 & 0 & 1 & 0 & 0 & $\mathrm{I}_{\mathrm{aa}}$ & Zero vector \\
8 & 0 & 0 & 1 & 0 & 0 & 1 & 0 & $\mathrm{I}_{\mathrm{bb}}$ & Zero vector \\
9 & 0 & 0 & 0 & 1 & 0 & 0 & 1 & $\mathrm{I}_{\mathrm{cc}}$ & Zero vector \\
10 & 0 & 1 & 1 & 1 & 0 & 0 & 0 & $\mathrm{I}_{\mathrm{d}}$ & Shoot - through zero vector \\
11 & 0 & 0 & 0 & 0 & 1 & 1 & 1 & $\mathrm{I}_{\mathrm{d}}$ & Shoot - through zero vector \\
\hline
\end{tabular}




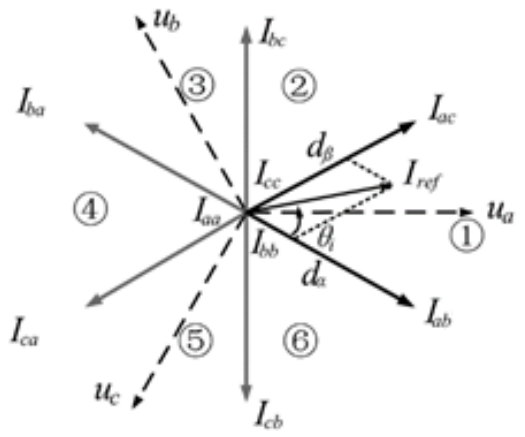

Figure 3. Space vector diagram of the rectifier stage

The duty cycles of the three vectors in sector 1 are calculated by:

$$
\begin{aligned}
& d_{\alpha}=m_{i} \sin \left(\frac{\pi}{6}-\theta_{i}\right) \\
& d_{\beta}=m_{i} \sin \left(\theta_{i}+\frac{\pi}{6}\right) \\
& d_{s}=\operatorname{Const}\left(d_{S} \leq 1-d_{\alpha}-d_{B}\right) \\
& d_{O r}=1-d_{\alpha}-d_{\beta}-d_{S}
\end{aligned}
$$

Where $m_{i}$ is the modulation index of rectifier stage, $\theta_{i}$ is the input current vector angle, $d_{\alpha}, d_{\beta}, d_{s}$, and $d_{O r}$ are the duty ratios of active vectors, shoot-through and zero vectors in one switching cycle, respectively. The diagram of the space vector for inverter stage is explained in Figure 4.

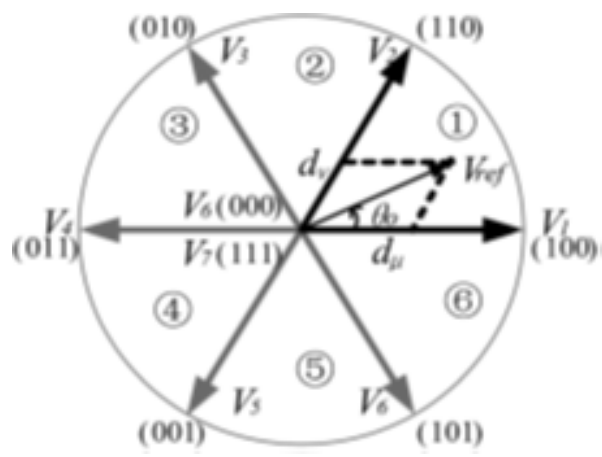

Figure 4. Space vector diagram of the inverter stage

The inverter stage is the same as traditional voltage source inverter, which consists of the six active vectors and the two zero vectors [25], the duty ratios in sector 1 as example are calculated by:

$$
\begin{aligned}
& d_{\mu}=m_{0} \sin \left(\frac{\pi}{3}-\theta_{i}\right) \\
& d_{v}=m_{0} \sin \theta_{0} \\
& d_{o i}=1-d_{\mu}-d_{v}
\end{aligned}
$$

Where $m_{0}$ is the modulation index of the inverter stage, $\theta_{0}$ is the output voltage vector angle, $d_{\mu}, d_{v}$ and $d_{o i}$ are the duty ratios of active vectors and zero vector of rectifier stage, respectively.

In one switching period, in order to obtain balanced three phase input current and three phase output voltage, the modulation pattern combines switching states of two stages. In the inverter stage, the switching

Modeling and simulation of quasi-Z-source indirect matrix converter for permanent ... (Ahmed M. Nori) 
pattern should divide into two groups since the dc-link has two positive line-to-line input voltages, the produced switching sequence is shown in the Figure 5. Calculation of the corresponding duty cycles can be obtained as:

$$
\begin{aligned}
& d_{u \alpha}=d_{u} \cdot d_{\alpha} \\
& d_{u \beta}=d_{u} \cdot d_{\beta} \\
& d_{v \alpha}=d_{v} \cdot d_{\alpha} \\
& d_{u \alpha}=d_{u} \cdot d_{\alpha} \\
& d_{o i \alpha}=d_{o i} \cdot d_{\alpha} \\
& d_{o i \beta}=d_{o i} \cdot d_{\beta}
\end{aligned}
$$

Where $d_{u \alpha}, d_{u \beta}, d_{v \alpha}, d_{u \alpha}, d_{o i \alpha}$, and $d_{o i \beta}$ are the duty cycles of different vectors of output voltage in one switching period.

From the Figure 5, while commutation in the rectifier stage occurs, the inverter operates on zero vector, which denotes that the dc-link current is zero throughout commutation. Thus, zero current switching is ensured on the rectifier stage throughout commutation, which reduces switching loss in rectifier stage, and this simplifies the commutating problem, which it is very complex with DMC [26]

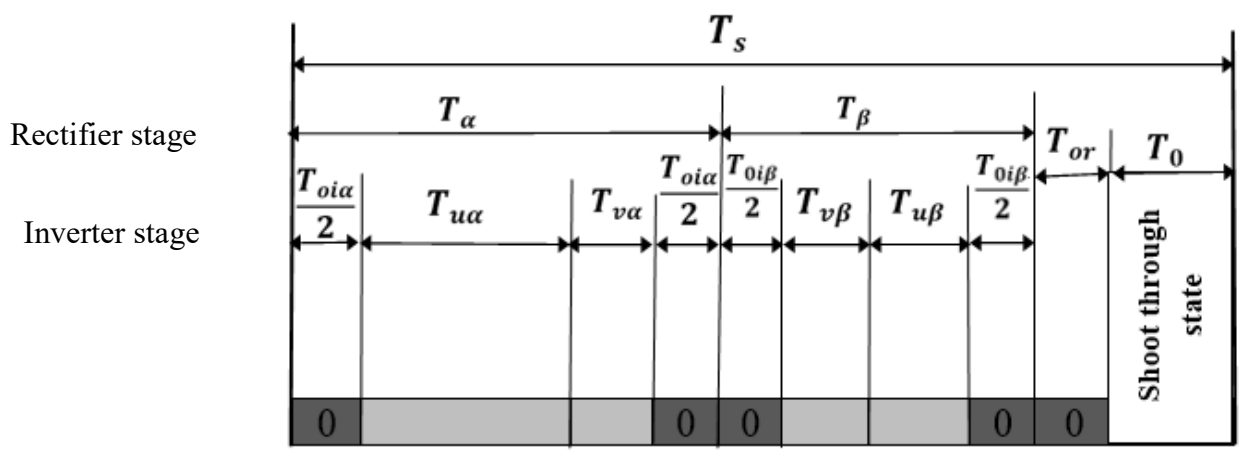

Figure 5. Switching sequence for proposed QZSIMC

\section{CIRCUIT ANALYSIS OF THE PROPOSED QZSIMC}

Figure 6 shows the circuit of the proposed QZSIMC feeds R-L load during the non-shoot through (NST) and shoot through (ST) states. Turn on / off of the bidirectional switches of QZS network $\left(S_{x}\right)$ will run it into two states. The first state is NST, as shown in the Figure 6(a) ; in this state, the front-end rectifier of IMC runs in traditional way and the three switches $S_{x}(\mathrm{x}=\mathrm{a}, \mathrm{b}, \mathrm{c})$ of QZSN are turned ON $\left(S_{x}=1\right)$. With the time period $(1-D) T_{s}$, the capacitors are charged by inductors; each output phase voltage of the QZSN is equal to the sum of voltages for two capacitors [27]. On the other hand, during the $S T$ state, switches $S_{x}(x=$ $a, b, c)$ are off $\left(S_{x}=0\right)$ as shown in Figure $6(\mathrm{~b})$, the three upper switches of front-end rectifier stage is short circuited, and the QZSN inductors for each phase are charged for one switching cycle, if $T_{0}$ is the time duration for shoot-through state, the shoot-through duty cycle is calculated as $D=T_{0} / T_{s}$. The output voltage of QZSN can be raised to the required value by controlling shoot-through duty. 


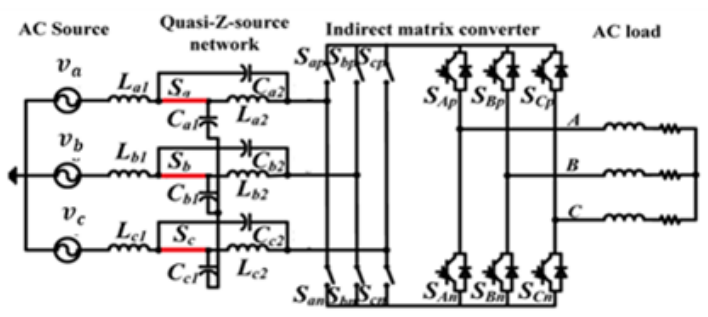

(a)

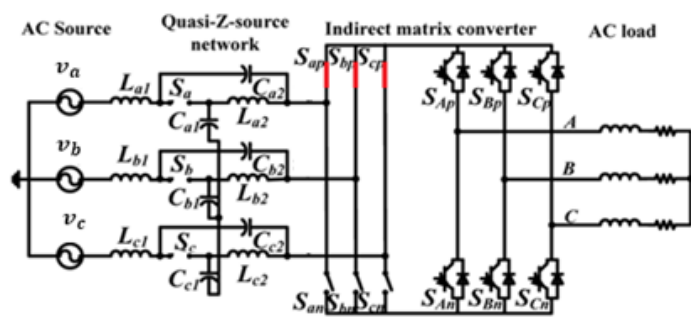

(b)

Figure 6. The circuit of the QZSIMC. (a) non-shoot-through state and (b) shoot-through state.

Due to $L_{a 1}=L_{a 2}=L_{b 1}=L_{a 2}=L_{c 1}=L_{c 2}=L$ and $=C_{a 2}=C_{b 1}=C_{b 2}=C_{c 1}=C_{c 2}=C$, from the Figure 6 (a), the following expressions can be obtained:

$$
\begin{aligned}
& {\left[\begin{array}{l}
v_{L_{a 1}} \\
v_{L_{b 1}} \\
v_{L_{c_{1}}}
\end{array}\right]=\left[\begin{array}{l}
v_{a} \\
v_{b} \\
v_{c}
\end{array}\right]-\left[\begin{array}{l}
v_{c_{a 1}} \\
v_{c_{b 1}} \\
v_{c_{c_{1}}}
\end{array}\right]-R_{L}\left[\begin{array}{l}
i_{L_{a 1}} \\
i_{L_{b 1}} \\
i_{L_{c 1}}
\end{array}\right]} \\
& {\left[\begin{array}{l}
v_{L_{a 2}} \\
v_{L_{b 2}} \\
v_{L_{c_{2}}}
\end{array}\right]=-\left[\begin{array}{l}
v_{c_{a 2}} \\
v_{c_{b 2}} \\
v_{c_{c_{2}}}
\end{array}\right]-R_{L}\left[\begin{array}{l}
i_{L_{a 2}} \\
i_{L_{b 2}} \\
i_{L_{c 2}}
\end{array}\right]} \\
& {\left[\begin{array}{l}
i_{C_{a 1}} \\
i_{C_{b 1}} \\
i_{C_{c 1}}
\end{array}\right]=\left[\begin{array}{l}
i_{L_{a 1}} \\
i_{L_{b 1}} \\
i_{L_{c 1}}
\end{array}\right]-\left[\begin{array}{l}
i_{a}^{\prime} \\
i_{b}^{\prime} \\
i_{c}^{\prime}
\end{array}\right]} \\
& {\left[\begin{array}{l}
i_{C_{a 2}} \\
i_{C_{b 2}} \\
i_{C_{c 2}}
\end{array}\right]=\left[\begin{array}{l}
i_{L_{a 2}} \\
i_{L_{b 2}} \\
i_{L_{c 2}}
\end{array}\right]-\left[\begin{array}{l}
i_{a}^{\prime} \\
i_{b}^{\prime} \\
i_{c}^{\prime}
\end{array}\right]}
\end{aligned}
$$

From the Figure 6 (b), it can be obtained

$$
\begin{aligned}
& {\left[\begin{array}{l}
v_{L_{a 1}} \\
v_{L_{b 1}} \\
v_{L_{c_{1}}}
\end{array}\right]=\left[\begin{array}{l}
v_{a} \\
v_{b} \\
v_{c}
\end{array}\right]+\left[\begin{array}{l}
v_{c_{a 2}} \\
v_{c_{b 2}} \\
v_{c_{c_{2}}}
\end{array}\right]-R_{L}\left[\begin{array}{l}
i_{L_{a 1}} \\
i_{L_{b 1}} \\
i_{L_{c 1}}
\end{array}\right]} \\
& {\left[\begin{array}{l}
v_{L_{a 2}} \\
v_{L_{b 2}} \\
v_{L_{c_{2}}}
\end{array}\right]=\left[\begin{array}{l}
v_{c_{a 1}} \\
v_{c_{b 1}} \\
v_{c_{c_{1}}}
\end{array}\right]-R_{L}\left[\begin{array}{l}
i_{L_{a 2}} \\
i_{L_{b 2}} \\
i_{L_{c 2}}
\end{array}\right]} \\
& {\left[\begin{array}{l}
i_{C_{a 1}} \\
i_{C_{b 1}} \\
i_{C_{c 1}}
\end{array}\right]=-\left[\begin{array}{l}
i_{L_{a 2}} \\
i_{L_{b 2}} \\
i_{L_{c 2}}
\end{array}\right]}
\end{aligned}
$$

Where $R_{L}$ is the stray resistance of inductors.

$$
\left[\begin{array}{l}
i_{C_{a 2}} \\
i_{C_{b 2}} \\
i_{C_{c 2}}
\end{array}\right]=-\left[\begin{array}{l}
i_{L_{a 1}} \\
i_{L_{b 1}} \\
i_{L_{c 1}}
\end{array}\right]
$$

In one $T_{s}$, the average values of QZSN inductor voltages and QZSN capacitor currents must be zero, $R_{L}=0$. Then, from Equation (14) - (21), the average equations can be obtained as: 


$$
\begin{aligned}
& {\left[\begin{array}{l}
v_{L_{a 1}} \\
v_{L_{b 1}} \\
v_{L_{c_{1}}}
\end{array}\right]=D\left(\left[\begin{array}{l}
v_{a} \\
v_{b} \\
v_{c}
\end{array}\right]+\left[\begin{array}{l}
v_{c_{a 2}} \\
v_{c_{b 2}} \\
v_{c_{c_{2}}}
\end{array}\right]\right)+(1-D)\left(\left[\begin{array}{l}
v_{a} \\
v_{b} \\
v_{c}
\end{array}\right]-\left[\begin{array}{l}
v_{c_{a 1}} \\
v_{c_{b 1}} \\
v_{c_{c_{1}}}
\end{array}\right]\right)=0} \\
& {\left[\begin{array}{l}
v_{L_{a 2}} \\
v_{L_{b 2}} \\
v_{L_{2}}
\end{array}\right]=D\left[\begin{array}{l}
v_{c_{a 1}} \\
v_{c_{b 1}} \\
v_{c_{c_{1}}}
\end{array}\right]+(1-D)\left(-\left[\begin{array}{l}
v_{c_{a 2}} \\
v_{c_{b 2}} \\
v_{c_{c_{2}}}
\end{array}\right]\right)=0} \\
& {\left[\begin{array}{l}
i_{C_{a 1}} \\
i_{C_{b 1}} \\
i_{C_{c 1}}
\end{array}\right]=D\left(-\left[\begin{array}{l}
i_{L_{a 2}} \\
i_{L_{b 2}} \\
i_{L_{c 2}}
\end{array}\right]\right)+(1-D)\left(\left[\begin{array}{l}
i_{L_{a 1}} \\
i_{L_{b 1}} \\
i_{L_{c 1}}
\end{array}\right]-\left[\begin{array}{l}
i_{a}^{\prime} \\
i_{b}^{\prime} \\
i_{c}^{\prime}
\end{array}\right]\right)=0} \\
& {\left[\begin{array}{l}
i_{C_{a 2}} \\
i_{C_{b 2}} \\
i_{c_{c 2}}
\end{array}\right]=D\left(-\left[\begin{array}{l}
i_{L_{a 1}} \\
i_{L_{b 1}} \\
i_{L_{c 1}}
\end{array}\right]\right)+(1-D)\left(\left[\begin{array}{l}
i_{L_{a 2}} \\
i_{L_{b 2}} \\
i_{L_{c 2}}
\end{array}\right]-\left[\begin{array}{l}
i_{a}^{\prime} \\
i_{b}^{\prime} \\
i_{c}^{\prime}
\end{array}\right]\right)=0}
\end{aligned}
$$

From Equation (22) -(25), the QZSN capacitor voltages and inductor currents of QZSN are:

$$
\begin{aligned}
& {\left[\begin{array}{l}
v_{c_{a 1}} \\
v_{c_{b 1}} \\
v_{c_{c_{1}}}
\end{array}\right]=\frac{(1-D)}{(1-2 D)}\left[\begin{array}{l}
v_{a} \\
v_{b} \\
v_{c}
\end{array}\right]} \\
& {\left[\begin{array}{l}
v_{c_{a 2}} \\
v_{c_{b 2}} \\
v_{c_{c_{2}}}
\end{array}\right]=\frac{D}{(1-2 D)}\left[\begin{array}{l}
v_{a} \\
v_{b} \\
v_{c}
\end{array}\right]} \\
& {\left[\begin{array}{l}
i_{L_{a 1}} \\
i_{L_{b 1}} \\
i_{L_{c 1}}
\end{array}\right]=\left[\begin{array}{l}
i_{L_{a 2}} \\
i_{L_{b 2}} \\
i_{L_{c 2}}
\end{array}\right]=\left[\begin{array}{l}
i_{a} \\
i_{b} \\
i_{c}
\end{array}\right]}
\end{aligned}
$$

From Equation (26) - (28), the output voltages and currents of QZSN are:

$$
\begin{aligned}
& {\left[\begin{array}{l}
i_{a}^{\prime} \\
i_{b}^{\prime} \\
i_{c}^{\prime}
\end{array}\right]=\frac{(1-2 D)}{(1-D)}\left[\begin{array}{l}
i_{a} \\
i_{b} \\
i_{c}
\end{array}\right]} \\
& {\left[\begin{array}{l}
v_{a}^{\prime} \\
v_{b}^{\prime} \\
v_{c}^{\prime}
\end{array}\right]=\frac{1}{1-2 D}\left[\begin{array}{l}
v_{a} \\
v_{b} \\
v_{c}
\end{array}\right]}
\end{aligned}
$$

Then the voltage boost factor $(B)$ can be expressed as:

$$
B=\frac{V_{i}^{\prime}}{V_{i}}=\frac{1}{1-2 D}(\mathrm{D}<0.5)
$$

Where $V^{\prime}{ }_{i}$ is defined as the amplitude of output voltages $\left(v_{a}^{\prime}, v_{b}^{\prime}, v_{c}^{\prime}\right)$ of QZSN and $V_{i}$ represents the input phase voltage amplitude. The relation between the boost factor and shoot through duty ratio is explained in the Figure 7. 


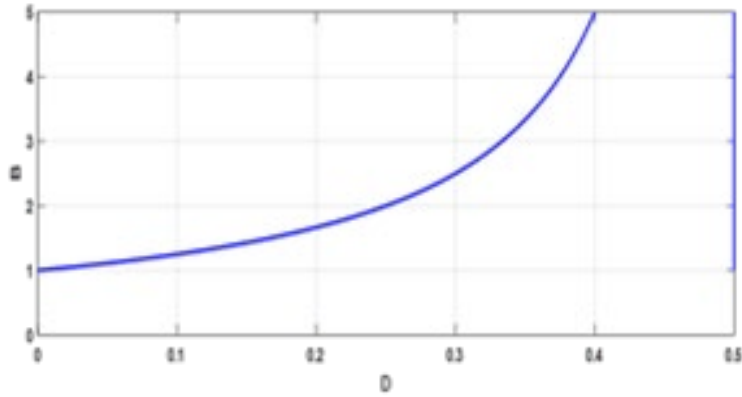

Figure 7. Voltage boost versus shoot-through duty ratio

The average dc-link voltage of the QZSIMC is

$$
V_{d c}^{\prime}=\frac{3}{2} V_{i} B m_{i} \cos \left(\theta_{i n}\right)
$$

Where $\theta_{\text {in }}$ is phase angle between output phase voltage and current of QZSN.

The modulation index $m_{0}$ of the inverter stage is

$$
m_{0}=\frac{\sqrt{3} V_{o}}{V_{d c}^{\prime}}
$$

Where $V_{o}$ is the amplitude of output phase voltage for QZSIMC, and the voltage gain $G$ of the proposed QZSIMC is obtained as:

$$
G=\frac{V_{o}}{V_{i}}=\frac{m_{0} V^{\prime} d c}{\sqrt{3} V_{i}}=\frac{\sqrt{3}}{2} \frac{m_{i} m_{0}}{1-2 D}=\frac{\sqrt{3}}{2} B m
$$

Where $m_{i}=1-\mathrm{D}$, the equation of voltage gain can be rewritten as:

$$
G=\frac{0.866(1-D) m_{0}}{1-2 D}
$$

\section{PARAMETERS DESIGN OF QZS NETWORK}

The switching current ripple and voltage ripple are significant items in choosing inductances and capacitances of QZSN, since the inductor of the QZSN must limit switching current ripple, and capacitor must limit switching voltage ripple, from shoot through and non-shoot through states the ripple of current and voltage can be expressed as:

$$
\Delta \dot{l}_{L 1}=\frac{v_{i} D(1-D)}{(1-2 D) f_{S} L}, \Delta v_{C}=\frac{i_{L_{a 1} D}}{f_{S} C_{2}}
$$

Where $i_{L_{a 1}}$ is the inductor current, $f_{s}$ denotes the switching frequency, $v_{i}$ denotes the input phase voltage. The desired inductor current ripple is assumed within $k_{1} I_{\text {rated }}$, and the required capacitor voltage ripple is assumed within $k_{2} V_{C_{\text {rated }}}$, where $k_{1}$ is ripple ratio of the current and $\mathrm{k}_{2}$ is the ripple ratio of the voltage, and $I_{\text {rated }}$ and $V_{C_{\text {rated }}}$ are the rated input current and the rated voltage on capacitor- $C_{2}$, respectively. From Equation (27), $V_{C_{\text {rated }}}=D V S /(1-2 D)$ with $V_{s}$ the root mean square value of grid voltage, then the QZSN inductance and capacitor are derived as following [28]:

$$
\begin{aligned}
& L \geq \frac{V_{i} D(1-D)}{f_{S} k_{1} I_{\text {rated }}(1-2 D)} \\
& C \geq \frac{I_{\text {rated }}}{f_{S} k_{2} V_{S}}(1-2 D)
\end{aligned}
$$




\section{CONTROL STRATEGY OF SHOOT THROUGH DUTY RATIO}

From Equation (35), It can be assumed that $m_{0}=1$. To ensure that $D$ is the best optimized choice, the value of $D$ is established as:

$$
D=\frac{V_{0}-0.866 V_{i}}{2 V_{0}-0.866 V_{i}}
$$

The flowchart of control algorithm for $D$ is shown in the Figure 8. the input of main flow chart includes amplitude of input phase voltage $V_{i}$ and the amplitude of output phase voltage $V_{0}$ of QZSIMC. When the required voltage gain $G$ is less than or equal 0.866 (the voltage gain of conventional IMC), it is not necessary to boost the voltage, the QZSN will only run as a second order filter with $D=0$, and $m_{i}=1$. When the requested $G$ is larger than 0.866 , the value of shoot through duty ratio $D$ is equal to $\frac{V_{0}-0.866 V_{i}}{2 V_{0}-0.866 V_{i}}$ and $m_{i}=1-D$, which achieves optimal operation of QZSIMC based drive system.

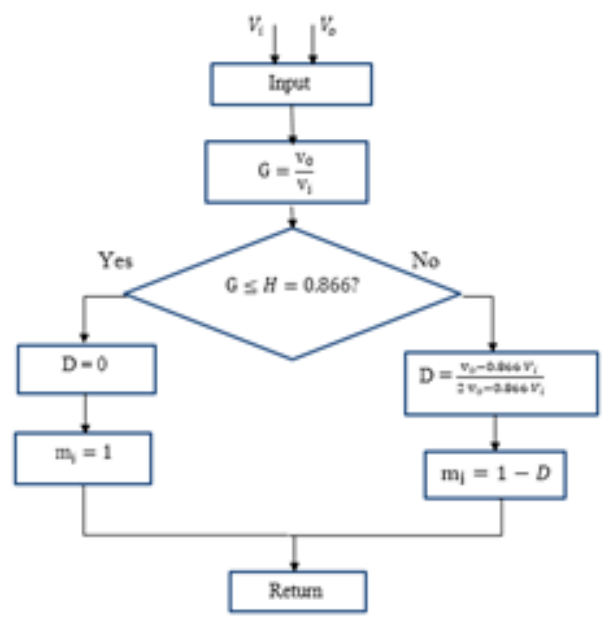

Figure 8. Flowchart optimal operation control of $D$

\section{MATHEMATICAL MODEL OF THE PMSM}

The replacement of rotor windings by permanent magnets give the permanent magnet motor many advantages including the removal of brushes, slip rings, and copper losses in the rotor's field winding. It makes the motor to run in a higher efficiency. The mathematical model of a PMSM is like to that of the wound rotor synchronous motor, since the stator of both motors are similar. To derive mathematical model, the following assumptions must be considered for PMSM [15].

a. Saturation is neglected.

b. The back emf is sinusoidal.

c. Eddy currents and hysteresis losses are negligible

The three phase PMSM voltages $(A-B-C)$ are converted to two phase voltages by Park-Clark transformation as:

$$
\left[\begin{array}{l}
v_{d} \\
v_{q} \\
0
\end{array}\right]=\left[\begin{array}{ccc}
\cos \theta & \cos (\theta-\alpha) & \cos (\theta-2 \alpha) \\
-\sin (\theta) & -\sin (\theta-\alpha) & -\sin (\theta-2 \alpha) \\
\frac{1}{2} & \frac{1}{2} & \frac{1}{2}
\end{array}\right]\left[\begin{array}{l}
v_{A} \\
v_{B} \\
v_{C}
\end{array}\right]
$$

Where, $\theta$ is the rotor angle and $\alpha=2 \pi / 3$

According to PMSM equivalent circuit in the rotor rotating reference frame, the voltage equations are given as [18]:

$$
\begin{aligned}
& v_{d}=R_{s} \cdot i_{d}+L_{d} \frac{d i_{d}}{d t}-\omega_{e} \lambda_{q} \\
& v_{q}=R_{s} \cdot i_{q}+L_{q} \frac{d i_{q}}{d t}+\omega_{e} \lambda_{d}
\end{aligned}
$$


Where $v_{\mathrm{d}}$ and $v_{q}$ are $d-q$ axis voltages, $i_{d}$ and $i_{q}$ are $d$ - $q$ axis currents, $\lambda_{q}$ and $\lambda_{d}$ are $d$ - $q$-axis fluxes and $\omega_{e}$ is the electrical rotor speed in $\mathrm{rad} / \mathrm{s}, R_{S}$ is the stator resistor. The fluxes of permanent magnet and the electromagnetic torque are given by:

$$
\begin{aligned}
& \lambda_{d}=L_{d} \cdot i_{d}+\lambda_{m} \\
& \lambda_{q}=L_{q} \cdot i_{q} \\
& T_{e}=\frac{3}{2} \frac{p}{2}\left(\lambda_{d} i_{q}-\lambda_{q} i_{d}\right)
\end{aligned}
$$

Where $p$ is the number of poles, and $\lambda_{m}$ is permanent magnet flux linkage, and the mechanical expression of torque is

$$
T_{e}=T_{L}+B \cdot \omega_{r}+J \cdot \frac{\mathrm{d} \omega_{r}}{\mathrm{~d} t}
$$

Where $\omega_{r}$ is the mechanical speed, $J$ is the inertia moment of the motor and $T_{L}$ is the load torque, $\omega_{r}$ is expressed as follows.

$$
\omega_{r}=\int\left(\frac{T_{e}-T_{L}-B \cdot \omega_{r}}{J}\right) \cdot \mathrm{d} t
$$

\section{VECTOR CONTROL Of PMSM}

Vector control is high-performance control technique which is equivalent to speed control method of DC machines [17]. It is observed from Equation (47) that motor speed can be controlled through controlling the delivered torque. For surface mounted PMSM, the $d$ and $q$ inductances are equal $\left(L_{d}=L_{q}\right)$ The generated torque is expressed as:

$$
T_{e}=\frac{3}{2} \frac{p}{2}\left(\lambda_{m} \cdot i_{q}\right)
$$

To obtain $i_{d}$ and $i_{q}$ from three- phase motor currents, Park-Clarke transformation is used, which consider a flux generating and torque of stator current components, respectively [19].

$$
\left[\begin{array}{l}
i_{d} \\
i_{q}
\end{array}\right]=\left[\begin{array}{crr}
\cos \theta & \cos (\theta-\alpha) & \cos (\theta-2 \alpha) \\
-\sin \theta & -\sin (\theta-\alpha) & -\sin (\theta-2 \alpha)
\end{array}\right]\left[\begin{array}{l}
i_{A} \\
i_{B} \\
i_{C}
\end{array}\right]
$$

The reference speed is compared with the actual motor speed and the resulting error is applied to the PI controller. The output of the PI controller is represented as $i_{q}$, while the reference of $i_{d}$ is set to zero. The references $i_{q}^{*}$ and $i_{d}^{*}$ are compared with transformed stator current and applied to another PI controllers. From the output of both PI controllers $(d-q)$ voltages can be generated. Thus, PI control loop for $i_{d}$ is used to provide $v_{d}$, and the rotor speed PI controller is used to get the reference $i_{q}^{*}$, which in turn provides $v_{q}$ with PI control loop for $i_{q}$, as shown in the Figure 9. In Equation (41) and (42), $\omega_{e}\left(L_{d} i_{d}+\lambda_{\mathrm{m}}\right)$ and $-\omega_{e} L_{q} i_{q}$ are coupling terms. If speed of motor is high, their effect cannot be neglected. In order to remove the coupling part, these two terms must be added to $(d-q)$ voltages. The decoupling control block, $v_{d}^{* *}$ and $v_{q}^{* *}$ can be calculated as:

$$
\begin{aligned}
& v_{d}^{* *}=-\omega_{e} L_{q} i_{q} \\
& v_{q}^{* *}=\omega_{e}\left(L_{d} i_{d}+\lambda_{\mathrm{m}}\right)
\end{aligned}
$$




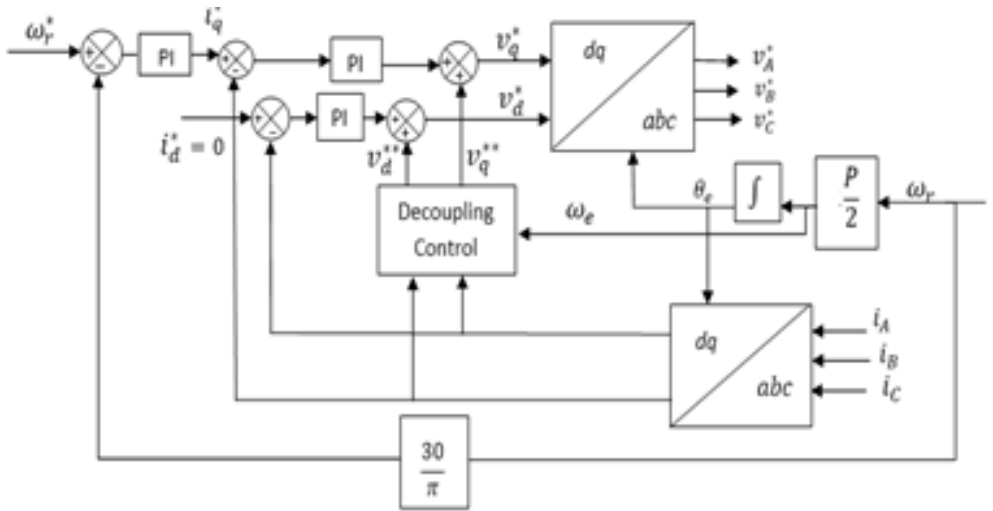

Figure 9. Vector control of PMSM

\section{QZSIMC BASED PMSM DRIVE}

In this section, the proposed converter is applied to PMSM drive. The vector control of the PMSM drive with QZSIMC is shown in Figure 10, which illustrates that the output voltages of QZSN are input for the rectifier stage, while the inverter stage supplies the motor with variable frequency and voltages. The generated switching signals are applied for power switches of QZSN, rectifier and inverter stages of QZSIMC.

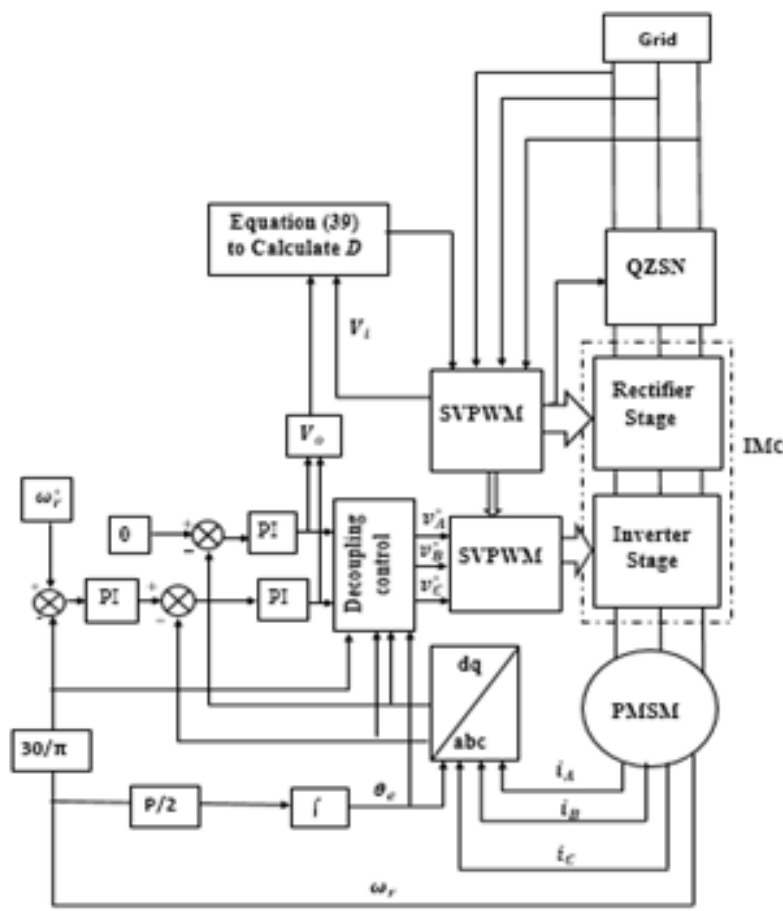

Figure 10. Block diagram of PMSM drive system

\section{SIMULATION RESULTS}

The Simulation results of QZSIMC-fed PMSM drive shown in Figure 10 are obtained using MATLAB/ Simulink 2015b, that is running on CORE i7 PC (2.4GHZ CPU) with 8 GB RAM. The parameters of the system are shown in Tables 2. The drive system is simulated under three cases to show advantage of proposed converter to motor drive and validate QZSIMC performance in transient and steady state. The first case is carried out with variable speed and fixed load, the second case is carried out with 
variable load at rated speed, and finally, the third case is implemented under rated speed and load with $40 \%$ input voltage sag.

Table 2. Parameters of drive system

\begin{tabular}{cc}
\hline \multicolumn{2}{c}{ QZSIMC parameters: } \\
\hline Parameters & Value \\
Three-phase voltage source & $220 \mathrm{~V} / 50 \mathrm{~Hz}$ \\
Inductance of QZSN & $5 \mathrm{mH}$ \\
Capacitance of QZSN $C_{1}$ & $10 \mu \mathrm{F}$ \\
Capacitance of QZSN $C_{2}$ & $30 \mu \mathrm{F}$ \\
Switching frequency & $10 \mathrm{KHz}$ \\
\hline PMSM parameters: \\
\hline Parameters & Value \\
Rated power & $1.1 \mathrm{~kW}$ \\
Rated speed & $3000 \mathrm{rpm}$ \\
DC voltage & $220 \mathrm{~V}$ \\
Stator inductance & $0.0085 \mathrm{H}$ \\
Stator resistance & $2.875 \Omega$ \\
Rotor moment of inertia & $0.0008 \mathrm{Kg} . \mathrm{m}^{2}$ \\
Friction factor & $0.001 \mathrm{~N} . \mathrm{m} . \mathrm{s}$ \\
Magnetic flux & $0.175 \mathrm{~Wb}$ \\
Number of pole pairs & 2 \\
Rated torque & $3 \mathrm{~N} . \mathrm{m}$ \\
\hline
\end{tabular}

\subsection{Case 1}

In this case, the simulation has been performed for the reference speeds of 1500 and $3000 \mathrm{rpm}$ with the simulation time of 2 seconds as shown in Figure 11(a) The initial condition of this simulation is given as follows: motor is loaded with value of $2 \mathrm{Nm}$, the initial speed response is from 0 to $1500 \mathrm{rpm}$, then the speed is increased to 3000 at time 1 second. The speed response shows that the actual speed of the system can track the actual value more quickly and smoothly, the response of torque is shown in Figure 11(b).

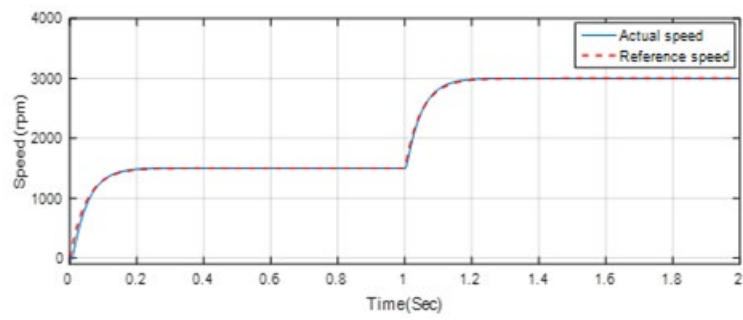

(a)

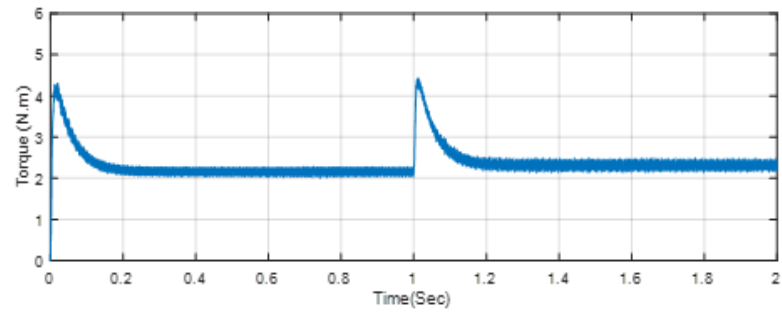

(b)

Figure 11. The simulation results for Case 1 (a) motor speed and (b) motor load torque

The source current and input voltage are shown in Figure 12(a), which demonstrates that the input power factor approximately is unity and the waveform of the source current is sinusoidal, and its value increases when the speed is varied from 1500 to $3000 \mathrm{rpm}$. The THD of the source current are $2.69 \%$ and $3.52 \%$ for speed of 1500 and $3000 \mathrm{rpm}$, respectively. The stator current waveform in Figure 12(b) has a THD of $2.52 \%$ and $3.04 \%$ for speeds 1500 and 3000 , respectively.

It is obvious from Figure 13(a) that the value of $D$ is equal to zero at speed of $1500 \mathrm{rpm}$ because of there is no need to boost voltage $(G<0.866)$, and QZSN will work as a second order filter. When the motor speed is raised from 1500 to $3000 \mathrm{rpm}$, the value of $D$ goes up from 0 to 0.107 since the value of required voltage gain of QZSIMC has become greater than the voltage gain of traditional IMC $(\mathrm{G}>0.866)$ as demonstrated in the figure 13(b), which is decided by demanded speed. As a result, the dc-link voltage and output voltage will boost to run the motor at rated speed, as shown in Figure 13(c) and 13(d), respectively. 


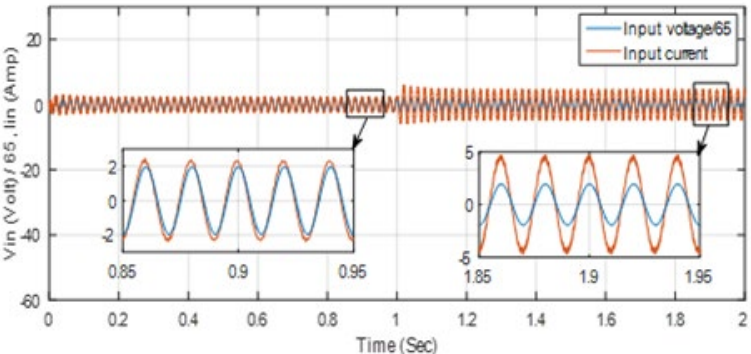

(a)

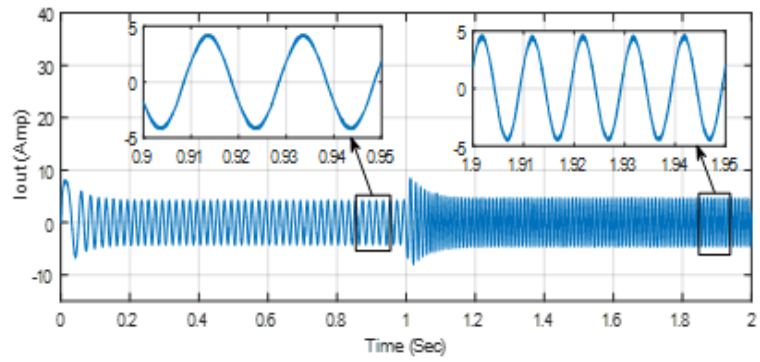

(b)

Figure 12. The simulation results for Case1 (a) phase-a input current and (b) phase-a output current

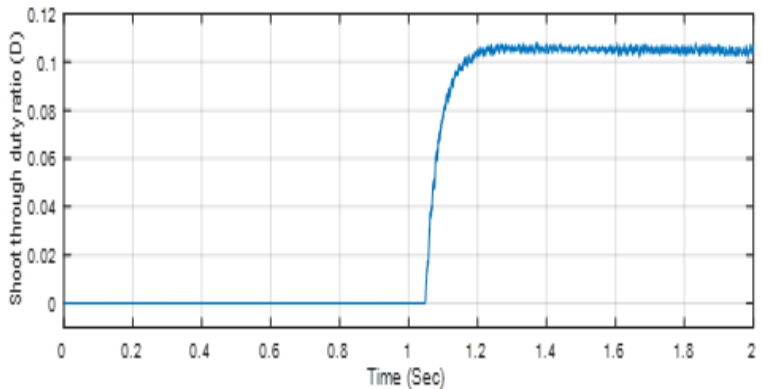

(a)

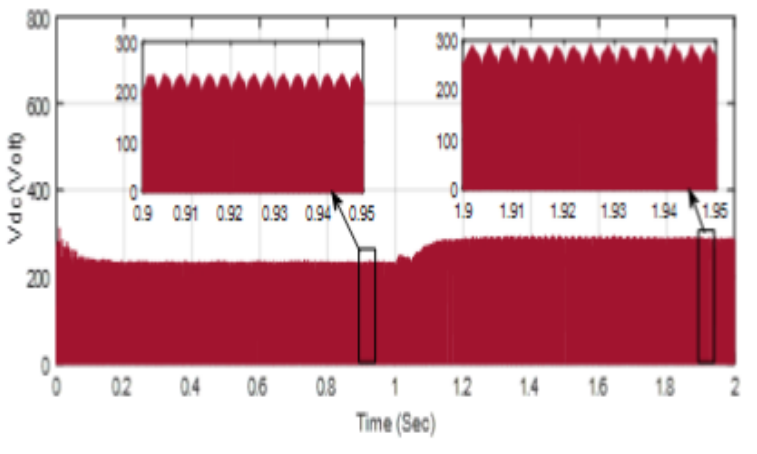

(c)

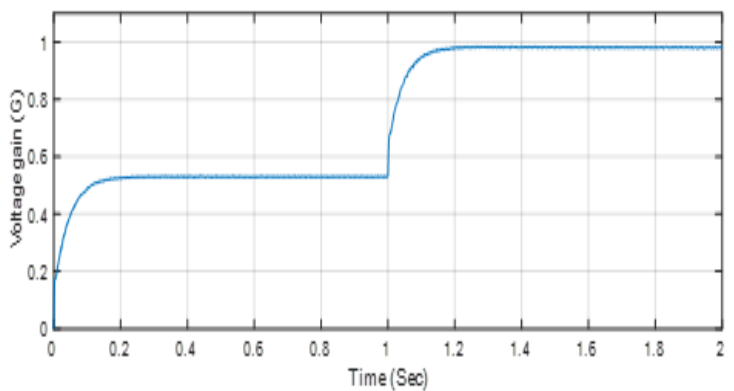

(b)

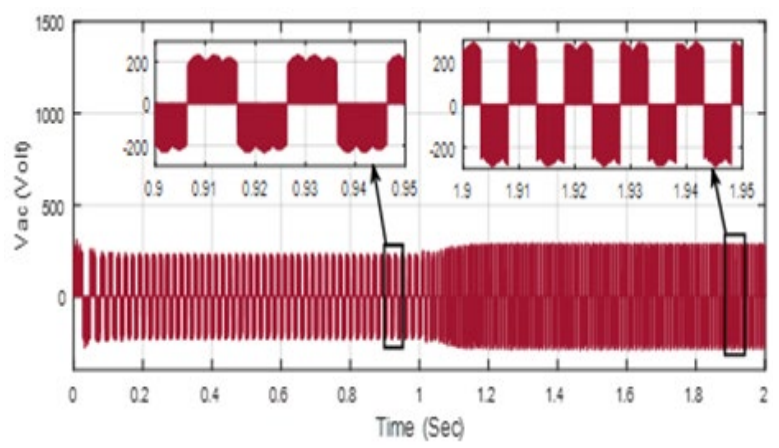

(d)

Figure 13. Simulation results for Case 1 (a) shoot through duty ratio, (b) output voltage gain of QZSIMC, (c) DC-link voltage and (d) output line voltage

\subsection{Case 2:}

In this case, the motor is run with rated speed of $3000 \mathrm{rpm}$ and loaded with $2 \mathrm{Nm}$ for the first 0.5 second of the period, after 0.5 second the motor load is increased to rated value of $3 \mathrm{Nm}$, as shown in Figure 14 (a). Figure 14 (b) shows a good dynamic response of speed during load change. As can be seen from the Figure 14(c) that PI controller fixes the magnetizing current at zero because of the permanent magnets, while the component of the current $i q$ tracks the load torque and has a value which is proportional to the load torque. 


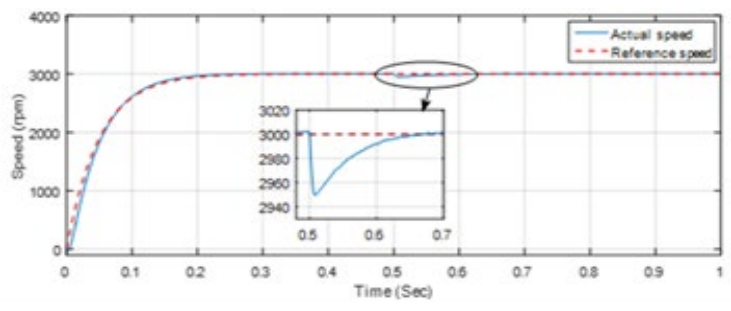

(a)

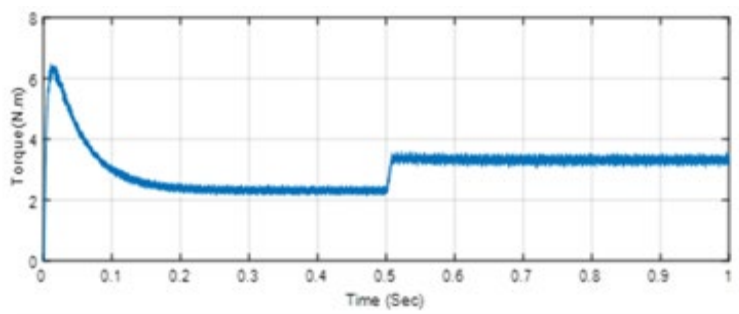

(b)

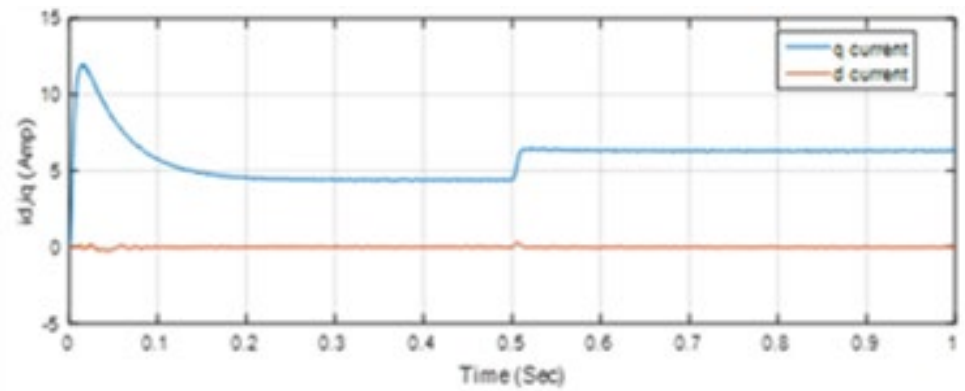

(c)

Figure 14. The simulation results for Case 2 (a) motor speed, (b) motor load torque and (c) id-iq currents

It is clear from Figure 15 (a) that the grid current is in phase with input voltage, hence the input power factor approximately is unity and the waveform of the source current is sinusoidal with THD of $3.2 \%$ and $3.4 \%$ at 2 and $3 \mathrm{Nm}$, respectively. The waveform of output current is shown in Figure 15(b) with a THD of $3.06 \%$ and $2.67 \%$ at 2 and $3 \mathrm{Nm}$, respectively.

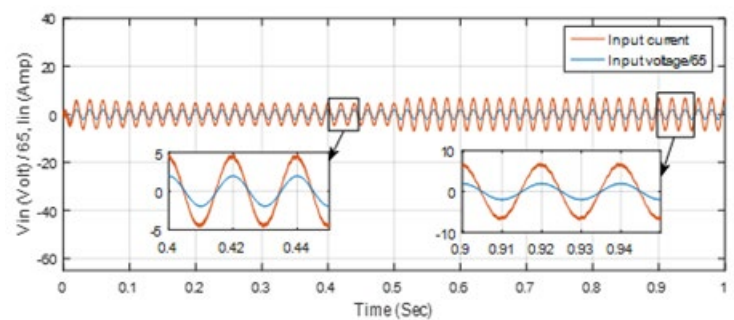

(a)

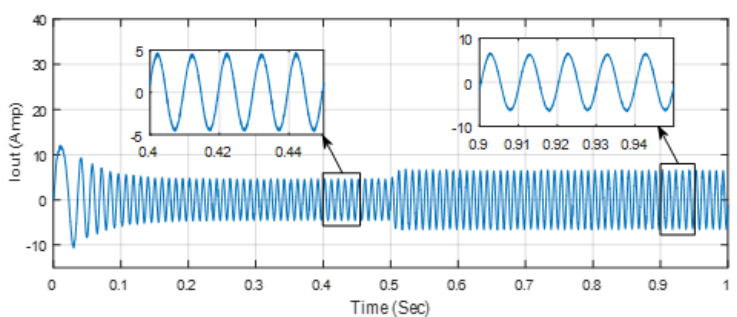

(b)

Figure 15. The simulation results for Case 2 (a) phase-a input current and (b) phase-A output current

The load torque step change causes increment of shoot through duty ratio from 0.107 to 0.14 as shown in Figure 16(a), since the required voltage gain of the PMSM is increased during load change, as shown in the Figure 16 (b). That means more energy is needed to the load side, which leads to boost the dclink voltage and the output voltage to desired level to meet the new load requirement by the motor, as shown in Figure 16(c) and 16(d), respectively. 


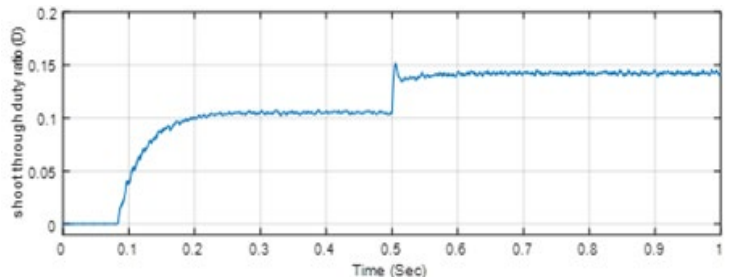

(a)

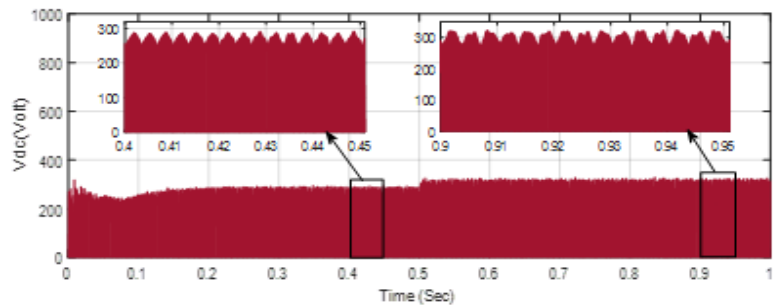

(c)

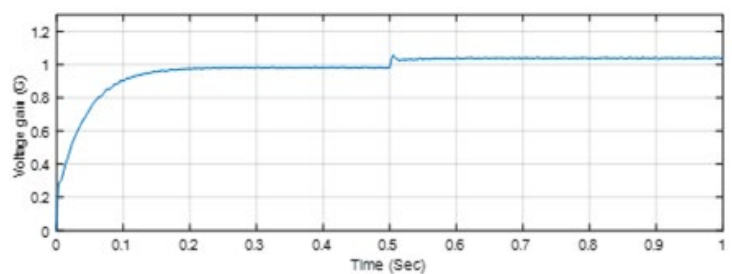

(b)

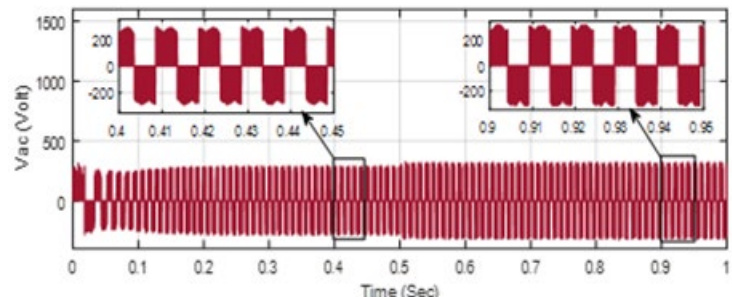

(d)

Figure 16. The simulation results for Case 2 (a) shoot through duty ratio, (b) output voltage gain of QZSIMC (c) DC-link voltage and (d) output line voltage

\subsection{Case 3:}

The motor drive system is tested under $40 \%$ voltage sag in input voltages from $220 / \sqrt{ } 3 \mathrm{~V}$ to $132 / \sqrt{ } 3$ $\mathrm{V}$ through a period of 0.5 second, as shown in the Figure 17(a). This voltage sag would raise the required voltage gain of the PMSM from 1.1 to 1.7 as shown in the Figure 17(b), which leads increase in the value of shoot through duty ratio from 0.14 to 0.325 as shown in the Figure 17(c), and consequently the dc-link voltage will be raised to desired level during voltage sag based on set speed, then regains its original value after voltage recovery, as clarified in the Figure 17 (d). The output line voltage has the same response of dclink voltage as shown in the Figure 17(e).

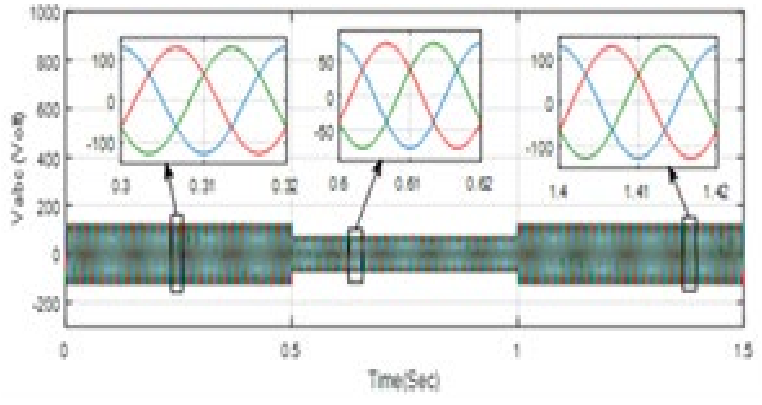

(a)

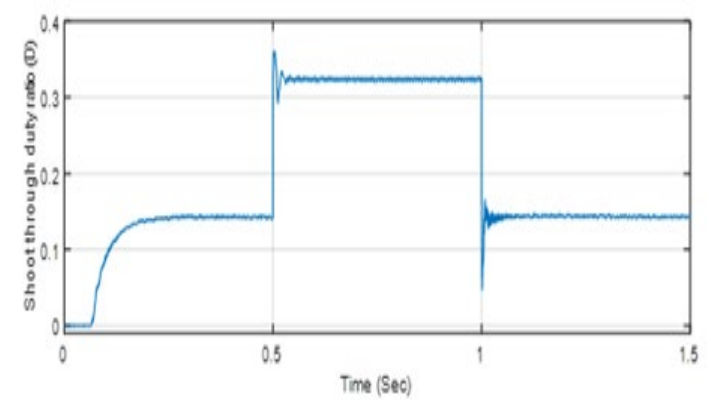

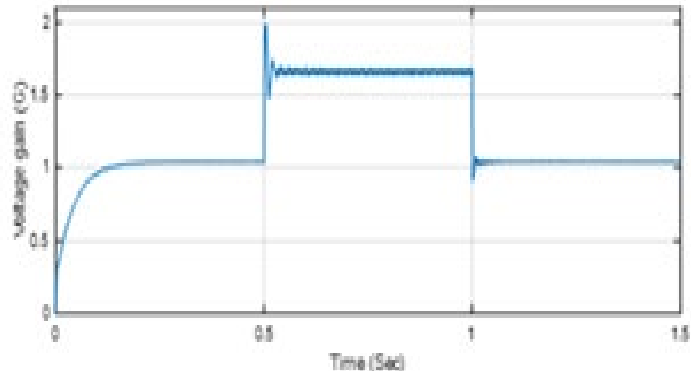

(b)

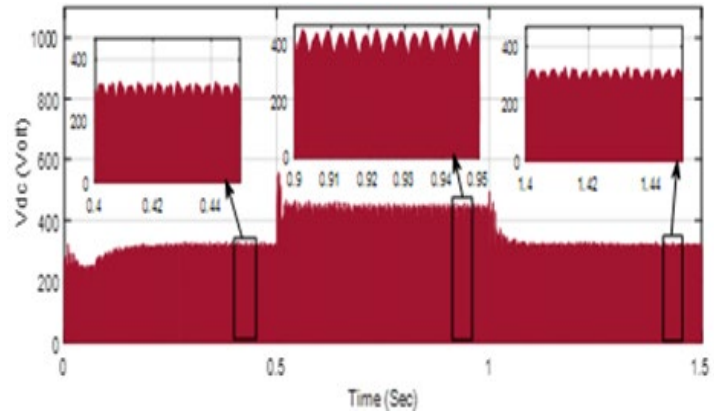


(c)

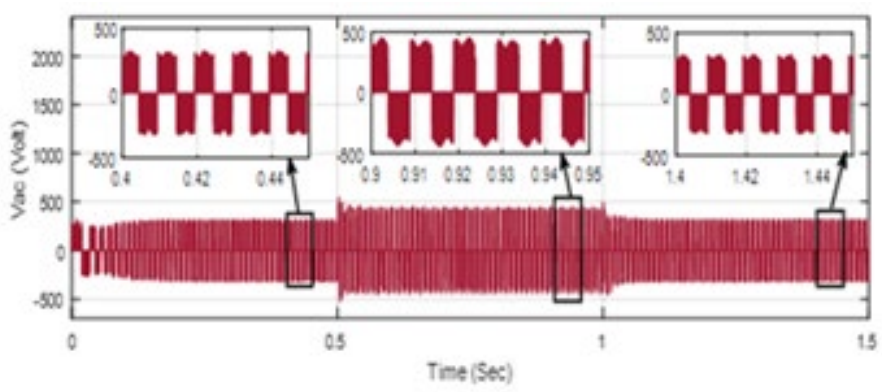

(e)

Figure 17. Simulation results for Case 3 (a) three-phase input voltage, (b) output voltage gain of QZSIMC (c) shoot through duty ratio (d) dc-linkVoltage and (e) output line voltage

The speed response in the Figure 18(a) shows that the speed is not affected and remains constant under $40 \%$ voltage sag, and the ripple in torque is increased during voltage sag as shown in the Figure 18(b).

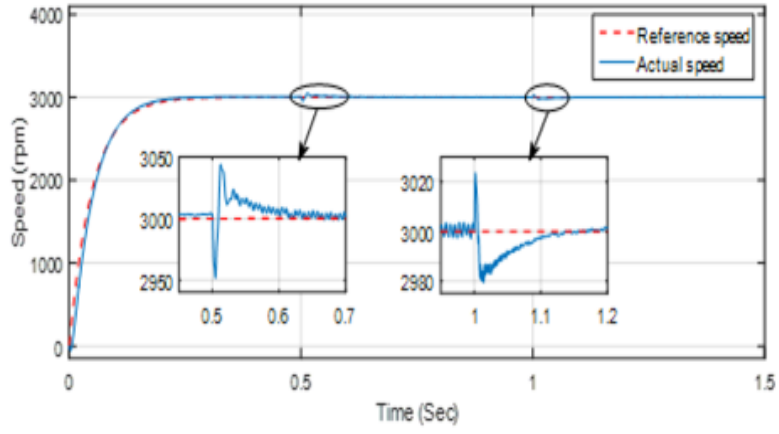

(a)

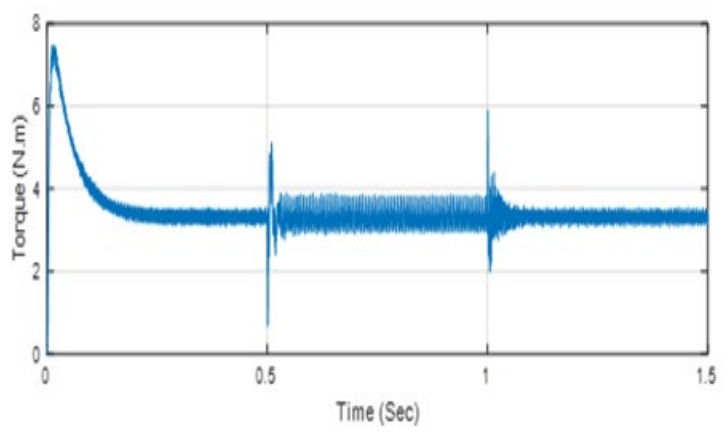

(b)

Figure 18. Simulation results for Case 3 (a) motor speed and (b) motor load torque

The input current and output current waveforms are shown in the Figure 19(a) and 19(b), respectively, they have the THD of $6.07 \%$ and $4.57 \%$ during voltage sag, respectively. The value of the input current will increase during a period of voltage sag, while the load current amplitude is not affected.

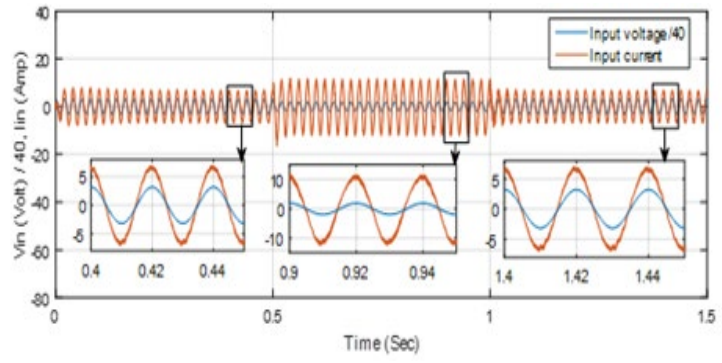

(a)

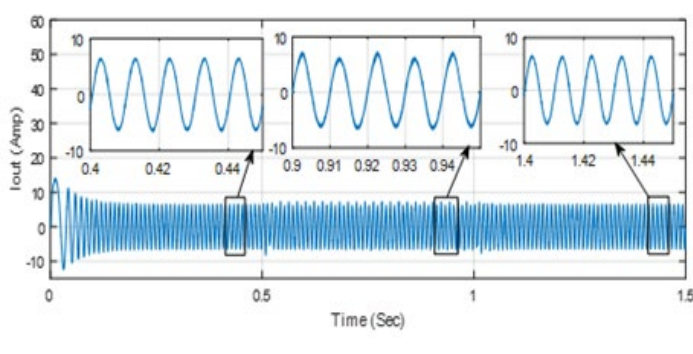

(b)

Figure19. Simulation results for Case 3 (a) phase-a input current, (b) phase-A output current 


\section{CONCLUSION}

This paper used three-phase QZSIMC to drive PMSM. The proposed converter had all the features of the conventional IMC in additional to the boost voltage ability, so the QZSIMC achieved voltage gain higher than the traditional converters. The input current was in continuous current mode, and the system does not require additional input filter. For variable speed PMSM drives, the voltage boost is only necessary for high-speed operation, while low-speed operation doesn't require any boost action. With the proposed control strategy of QZSIMC for PMSM drives, the simulation results show that the optimal selection of $D$ is achieved to meet the demanded voltage and validate the performance motor drive under different conditions.

\section{ACKNOWLEDGEMENTS}

The authors would like to thank the Department of Electrical Engineering, College of Engineering, University of Mustansiriyah, Iraq for their support and providing the facilities.

\section{REFERENCES}

[1] D. Sri Vidhya, T. Venkatesan," A Review on Performance Analysis of Matrix Converter Fed AC Motor Drive," International Journal of Power Electronics and Drive System (IJPEDS), vol. 7, no. 1, pp. 85-93 March 2016.

[2] T. Friedli, J. W. Kolar, J. Rodriguez, and P. W. Wheeler, "Comparative Evaluation of Three-Phase AC-AC Matrix Converter and Voltage DC-Link Back-to-Back Converter Systems, " IEEE Transactions on Industrial Electronics, vol. 59, no. 12, pp. 4487-4510, December 2012.

[3] Wei L, Lipo TA. ,"A novel matrix converter topology with simple commutation, " IEEE industry Applications Society Conference, Chicago, USA, pp. 1749-1754, 30 Sept.- 4 Oct. 2001.

[4] P. W. Wheeler, J. Rodriguez, J. C. Clare, and L. Empringham, "Matrix converter: A technology review," IEEE Trans. Ind. Electron., vol. 49, no. 2, pp. 276-288, Apr. 2002.

[5] M. Jussila and H. Tuusa, "Comparison of Direct and Indirect Matrix Converters in Induction Motor Drive", 32nd Annual Conference on IEEE Industrial Electronics, IECON 2006, pp.1621,1626, 6-10 Nov. 2006.

[6] C. Klumpner, F. Blaabjerg, I. Boldea, and P. Nielsen, "New modulation method for matrix converters," IEEE Transactions on Industry Applications, vol. 42, pp. 797-806, May-Jun 2006.

[7] Y. D. Yoon and S. K. Sul, "Carrier-based modulation technique for matrix converter," IEEE Transactions on Power Electronics, vol. 21, pp. 1691-1703, Nov 2006.

[8] Karaman E., Farasat M., Trzynadlowski A., "A comparative study of series and cascaded Z-source matrix converters," IEEE Trans. Ind. Electron., vol.61, no.10, pp.5164-5173, Oct. 2014

[9] W. Song, Y. Zhong, H. Zhang, X. Sun, Q. Zhang, W. Wang, "A study of Z-source dual-bridge matrix converter immune to abnormal input voltage disturbance and with high voltage transfer ratio," IEEE Trans. Ind. Informat., vol.9, no.2, pp.828-838, May 2013.

[10] B. Ge, Q. Lei, W. Qian, F. Z. Peng, "A family of Z-source matrix converters," IEEE Trans. Ind. Electron., vol.59, no.1, pp.35-46, Jan. 2012.

[11] S. Liu, B. Ge, H. Abu-Rub, F. Z. Peng, and Y. Liu, "Quasi-Z-source matrix converter-based induction motor drives," in IECON 2012 - $38^{\text {th }}$ Annual Conference on IEEE Industrial Electronics Society, pp.5303-5307, 25-28 Oct. 2012

[12] G. Feng, W. Qi, B. Zhang and C. Li, "Analysis and comparison of three-phase variable frequency PMSM with single-phase induction motor in household appliances," 2011 International Conference on Electrical Machines and Systems, Beijing, pp. 1-5, 2011.

[13] A. Kamalaselvan and S. Lenin Prakash," Modeling Simulation and Analysis of Closed Loop Speed Control of PMSM Drive System,"International Conference on Circuit, Power and Computing Technologies (ICCPCT),2014.

[14] Hanan Mikhael D. Habbi and Sara T. Rashed," PI and Fuzzy Speed Controllers for PM Synchronous Motor Drive," International Journal of Computer Applications, vol .149, no. 1, September 2016

[15] Pragasen Pillay and Ramu Krishnan,"Control Characteristics and Speed Control Design for a High Performance PMSM Drive," IEEE Transaction on power Electronics, vol .5, no. 2, April,1990.

[16] Hao Zhu, Xi Xiao and Yongdong Li," PI Type Dynamic Decoupling Control Scheme for PMSM High Speed Operation,"IEEE Applied Power Electronics Conference and Exposition (APEC),2010.

[17] Z. Mahmood, "Speed Performance Based Vector-Controlled Permeant Magnet Synchronous Motor Fed by Indirect Matrix Converter," [M. Sc thesis], Department of Electrical Engineering, University of Al-Mustansiriyah, 2018.

[18] K. Vinothkumar, "Simulation and Comparison of SPWM and SVPWM Control for Three Phase Inverter," ARPN Journal of Engineering and Applied Sciences, Vol. 5, No. 7, July-2010.

[19] L. Huber, and D. Borojevic, "Space vector modulated three-phase to three-phase matrix converter with input power factor correction," IEEE Trans. Ind. Applic., vol. 31, pp. 1234-1246, Nov./Dec. 1995.

[20] S. Liu, B. Ge, Y. Liu, H. Abu-Rub, R. S. Balog and H. Sun, "Modeling, Analysis, and Parameters Design of LCFilter-Integrated Quasi-Z Source Indirect Matrix Converter," IEEE Trans. Power Electron., vol.31, no. 11, pp. 7544-7555, Nov. 2016

[21] Shuo Liu1, Baoming Ge, Xuyang You1, Xinjian Jiang, Haitham Abu- Rub and Fang Zheng Peng, "A novel quasiZ-source indirect matrix converter," The International Journal of Circuit Theory and Applications Int. J. Circ. Theor. Appl., 2015; 43:438-454 
[22] B. Nayak, S. S. Dash, and S. Kumar, "Proposed method for shoot-through in three phase ZSI and comparison of different control techniques," International Journal of Power Electronics and Drive System (IJPEDS), vol. 5, no. 1, pp. 32-44, 2014

[23] Noor Mazliza Badrul Sham, Shamsul Aizam Zulkifli, Ronald Jackson" i-Capacitor Voltage Control for PV Zsource System with Enhanced Shoot-through," International Journal of Power Electronics and Drive System (IJPEDS), vol. 9, no. 4, pp. 1899-1911,4, December 2018.

[24] S. Liu, B. Ge, H. Abu-Rub, and F. Z. Peng. "Modeling, analysis, and motor drive application of quasi-Z-source indirect matrix converter," COMPEL: The International Journal for Computation and Mathematics in Electrical and Electronic Engineering, vol. 33 no. 1/2, pp. 28-28, 2014

[25] Xuyang You, Baoming Ge, Shuo Liu, Ning Nie, Xinjian Jiang and Haitham Abu-Rub, "Common mode voltage reduction of quasi-Z source indirect matrix converter," International Journal of Circuit Theory and Applications, March 2015.

[26] Shuo Liu, Baoming Ge, Xinjian Jiang, H. Abu-Rub, Fang Zheng Peng, "Simplified quasi-Z source indirect matrix converter," International Journal of Circuit Theory and Applications, Oct 2014.

[27] S. Vidhya, T. Venkatesan, "Quasi-Z-source indirect matrix converter fed induction motor drive for flow control of dye in paper mill," IEEE Trans. Power Electron., vol. PP, no.99, pp.1-10, 2016.

[28] Omar Ellabban, Haitham Abu-Rub and Ge Baoming, "A Quasi-Z-Source Direct Matrix Converter feeding A Vector Controlled Induction Motor Drive," IEEE Journal of Emerging and Selected Topics in Power Electronics, vol. 03, no. 2, pp. 339-348, June 2015. 